Société d'histoire de la révolution de 1848 et des

révolutions du XIXe siècle

$46 \mid 2013$

L'espace du politique en Allemagne au XIX' siècle

\title{
Heinrich Heine, Lutetia. Correspondances sur la politique, l'art et la vie du peuple
}

Traduction, annotation et postface par Marie-Ange Maillet, Bibliothèque franco-allemande, Paris, Le Cerf, 2011, 368 p. ISBN : 978-2-204-09328-9. 38 euros

\section{Delphine Diaz}

\section{OpenEdition}

\section{Journals}

Édition électronique

URL : http://journals.openedition.org/rh19/4471

DOl : $10.4000 /$ rh 19.4471

ISSN : $1777-5329$

Éditeur

La Société de 1848

Édition imprimée

Date de publication : 1 juin 2013

Pagination : 204-206

ISSN : 1265-1354

Référence électronique

Delphine Diaz, «Heinrich Heine, Lutetia. Correspondances sur la politique, l'art et la vie du peuple », Revue d'histoire du XIXe siècle [En ligne], 46 | 2013, mis en ligne le 13 janvier 2014, consulté le 22 septembre 2020. URL : http://journals.openedition.org/rh19/4471 ; DOl : https://doi.org/10.4000/rh19.4471

Ce document a été généré automatiquement le 22 septembre 2020.

Tous droits réservés 


\section{Heinrich Heine, Lutetia. Correspondances sur la politique, l'art et la vie du peuple}

Traduction, annotation et postface par Marie-Ange Maillet, Bibliothèque franco-allemande, Paris, Le Cerf, 2011, 368 p. ISBN : 978-2-204-09328-9. 38 euros

\section{Delphine Diaz}

\section{RÉFÉRENCE}

Heinrich Heine, Lutetia. Correspondances sur la politique, l'art et la vie du peuple, traduction, annotation et postface par Marie-Ange Maillet, Bibliothèque franco-allemande, Paris, Le Cerf, 2011, 368 p. ISBN : 978-2-204-09328-9. 38 euros.

1 Les éditions du Cerf rassemblent dans la collection "Bibliothèque franco-allemande » des écrits d'Allemands sur la France et de Français sur l'Allemagne des $\mathrm{XVIII}^{\mathrm{e}}$ et $\mathrm{XIX}^{\mathrm{e}}$ siècles, s'inscrivant ainsi dans la perspective d'une histoire des "transferts culturels » qui s'est prioritairement penchée sur les échanges intellectuels entre les deux rives du Rhin. Les textes de Heinrich Heine ont été placés au centre même de cette collection dirigée par Michel Espagne, depuis la réédition du portrait au vitriol de Ludwig Börne (1993), jusqu'à celle des Tableaux de voyage (2000) et des Poèmes tardifs (2003), en passant par le célèbre recueil De la France (1996).

2 Lutetia, second ensemble d'articles sur la France écrits par Heine sous la monarchie de Juillet, a une histoire complexe, qui mérite ici d'être retracée. Ce recueil rassemble près de soixante-dix articles publiés par Heine dans la Gazette universelle d'Augsbourg entre 1840 et 1843, alors qu'il séjournait en exil volontaire depuis mai 1831 à Paris, y jouant à la fois le rôle de correspondant pour la presse germanique et de rédacteur pour certains périodiques français, comme la Revue des Deux Mondes, L'Europe littéraire, ou encore la Nouvelle Revue germanique. Les articles écrits en allemand au début des années 
1840 pour la Gazette universelle d'Augsbourg, l'un des quotidiens les plus lus outre-Rhin, ont fait l'objet d'une première édition allemande chez Julius Campe en 1854. C'est à partir de cette version, telle qu'elle a été intégrée à l'édition critique des œuvres intégrales de Heine parue à Düsseldorf entre 1988 et 1991, qu'a travaillé Marie-Ange Maillet, dont elle nous livre ici une traduction française.

Cette version germanique de l'œuvre ne doit pas être confondue avec celle établie en français sous le titre de Lutèce par les soins de Heine lui-même, mais d'un Heine malade, profitant de ses derniers moments d'activité et de lucidité pour publier ses Euvres complètes chez Lévy, entre 1854 et 1855 . Ces dernières années, Lutèce a fait l'objet d'un regain d'intérêt: en témoigne la réédition publiée par Ephraïm Harpaz aux éditions Slatkine en 1979, et surtout celle, plus récente, de Patricia Baudouin aux éditions La Fabrique en $2008^{1}$. Comme l'a souligné Lucien Calvié, le texte issu des Cuvres complètes parues en français est finalement le seul qui ait été revu, contrôlé et authentifié par Heine lui-même à la fin de son existence ${ }^{2}$. Néanmoins, il s'avère particulièrement utile de pouvoir confronter cette version à celle de Lutetia, ici restituée par Marie-Ange Maillet dans une traduction française. Par rapport à Lutèce, Lutetia comprend en effet plusieurs articles qui avaient été remaniés, censurés ou tout bonnement supprimés dans l'édition française chez Lévy en 1855.

4 Le destin éditorial particulièrement complexe des articles écrits par Heine pour la Gazette d'Augsbourg ne doit toutefois pas éclipser le profond intérêt de cette œuvre, qui est le pendant, pour les années 1840, du recueil intitulé De la France, rassemblant des articles écrits au début de la monarchie de Juillet. Lutetia éclaire d'abord la vie politique de la capitale où Heine séjourne alors en exil, en se penchant tout particulièrement sur les rapports de forces entre les différents pouvoirs de la monarchie parlementaire, et sur les diverses interprétations que donnent de ce régime politique ses principaux protagonistes, Louis-Philippe, Guizot et Thiers. Heine porte aussi un regard critique sur l'actualité internationale la plus brûlante, comme le prouve son intérêt marqué pour le scandale des Juifs de Damas ou pour la «question d'Orient». Mais contrairement au recueil d'articles De la France, qui était essentiellement tourné vers l'actualité politique, c'est également à la vie culturelle et intellectuelle que s'intéresse Lutetia à travers les nombreuses pages, souvent satiriques, que Heine y consacre aux écrivains, peintres et musiciens qui animaient alors une scène artistique parisienne particulièrement cosmopolite (le «divin» Rossini, le «maestro Meyerbeer », ou encore Liszt, excellent scénographe de ses propres succès).

Pour mettre en valeur l'intérêt de cette chronique de la vie politique et intellectuelle du Paris des années 1840, l'édition de Marie-Ange Maillet, germaniste et spécialiste de Heine, s'accompagne d'un appareil critique d'une vingtaine de pages. La postface s'avère particulièrement utile pour comprendre le sort de ce texte paru dans les deux langues et retouché à de nombreuses reprises par l'auteur et par ses collaborateurs, qu'il s'agisse du rédacteur en chef de la Gazette d'Augsbourg, de traducteurs ou d'éditeurs. On peut regretter néanmoins l'absence de chronologie et de bibliographie, qui étaient en revanche présentes dans l'édition de Lutèce publiée aux éditions La Fabrique. Des biographies succinctes des principaux acteurs de la vie politique et intellectuelle française, évoqués ou seulement mentionnés, parfois de manière sibylline, par les articles de Heine, auraient également été les bienvenues, afin de permettre au lecteur d'aujourd'hui de mieux réinscrire cette œuvre dans son contexte historique. Il n'en reste pas moins que cette première traduction française de Lutetia 
permettra d'enrichir la connaissance en France de l'œuvre de Heine, véritable passeur entre deux cultures.

\section{NOTES}

1. Cf. le compte rendu de cet ouvrage par Sylvie Aprile paru dans la Revue d'histoire du XIX ${ }^{\mathrm{e}}$ siècle, $n^{\circ}$ 38, 2009/1, p. 146-147.

2. Lucien Calvié, « Le Soleil de la liberté », Henri Heine (1797-1856). L'Allemagne, la France et les révolutions, Paris, Presses de l'université Paris-Sorbonne, 2006, p. 23. 